\title{
PROPOSTA DE UM ALGORITMO GENÉRICO BASEADO EM RNA PARA A PROTEÇÃO DE DISTÂNCIA DE LINHAS DE TRANSMISSÃO
}

\author{
Santos, R.C.* \\ ricardo.santos@poli.usp.br
}

\author{
Senger, E.C.* \\ senger@pea.usp.br
}

\author{
*PEA-POLI-USP \\ Av. Professor Luciano Gualberto 158, Prédio da Engenharia Elétrica, \\ CEP 05508-900 - São Paulo - SP
}

\begin{abstract}
This work presents an algorithm based on Artificial Neural Networks (ANN) for the implementation of a distance relay to be used in transmission lines. The main contribution of the proposed algorithm is the possibility to protect any transmission line (generic algorithm) independently of its voltage level or configuration, without a new ANN process training. Therefore, unlike previous works, this algorithm does not need any adjustment in the ANN architecture and its parameters, when applied to different electric systems. This characteristic is the main differential of the solution presented here, when compared to other ANN based algorithms, always developed to operate in only one particular transmission line (tower geometry, cable, length and pre-determined voltage level), which makes them unfit to be implemented in a commercial relays.
\end{abstract}

KEYWORDS: Neural Networks, Protection, Relays, Transmission Line.

\section{RESUMO}

Neste artigo é apresentado um algoritmo baseado em Redes Neurais Artificiais (RNA) para a implementação de uma proteção de distância de linhas de transmissão. Tal algoritmo

Artigo submetido em 14/09/2004

1a. Revisão em 30/03/2005

2a. Revisão em 31/05/2005

Aceito sob recomendação do Editor Associado

Prof. Takashi Yoneyama possui como principal contribuição a possibilidade de ser utilizado em qualquer linha de transmissão, independentemente da configuração ou do nível de tensão desta, dispensando um novo processo de treinamento da rede neural. Portanto, este algoritmo não necessita de nenhum ajuste na topologia ou nos parâmetros da RNA (retreinamento), quando aplicado à diferentes sistemas elétricos. Esta característica diferencia a solução proposta, das demais baseadas em RNA, que são sempre projetadas para operarem numa única e exclusiva linha de transmissão (geometria de torre, condutores, comprimento e nível de tensão pré-determinados), inviabilizando sua implementação num relé comercial.

PALAVRAS-CHAVE: Redes Neurais, Relés, Proteção, Linhas de Transmissão.

\section{INTRODUÇÃO}

Atualmente, inúmeros trabalhos são publicados ressaltando os promissores resultados obtidos quando se emprega algoritmos baseados em RNA na proteção de linhas de transmissão. Entretanto, apesar desses resultados, tais algoritmos não são utilizados na prática devido, principalmente, ao fato de que estes operam satisfatoriamente numa única linha de transmissão (a linha para a qual a rede foi treinada).

Entre os trabalhos publicados, destacam-se os algoritmos propostos por Dalstein (1996), Kezunovic (1996), Vázquez (1996), Jiali (1997), Oleskovics (1998), Li (2001), Vasilic (2002), os quais fazem parte de um grupo de algoritmos que atuam como classificadores, ou seja, indicam se a falta 
encontra-se dentro ou fora da zona de proteção do relé. Já os trabalhos publicados por Salat (2000), Tawfik (2001) e Bouthiba (2004) fazem parte de um grupo de algoritmos que atuam como aproximadores de função, indicando, direta ou indiretamente, a distância da falta. È importante ressaltar que todos os algoritmos propostos operam corretamente somente para a linha de transmissão que gerou os sinais utilizados no treinamento das RNA.

Considerando os algoritmos referenciados, os propostos por Jiali (1997), Li (2001) e Bouthiba (2004) utilizam a técnica de Fourier para extrair os fasores da componente fundamental dos sinais de tensão e corrente, os quais são utilizados como entradas das RNA. Já os demais algoritmos apresentados, com exceção do trabalho de Tawfik (2001), utilizam como entradas das redes as amostras instantâneas dos sinais de tensão e/ou corrente.

Visando contornar as restrições existentes e viabilizar a utilização de algoritmos baseados em RNA, este artigo apresenta um algoritmo, baseado nesta técnica, que calcula com precisão, para qualquer linha de transmissão, a impedância de falta vista pelo relé. A partir desse resultado, utilizando-se o mesmo procedimento dos algoritmos convencionais, testa-se a impedância calculada frente à característica de atuação do relé (MHO ou QUADRILATERAL), visando determinar se a falta encontra-se dentro ou fora da zona de proteção deste.

Para que o algoritmo proposto atenda o objetivo fixado são desenvolvidos elementos de medição de impedância (elementos de fase e elementos de terra) baseados em RNA. Nestes elementos de medição existe um esquema com etapas de pré e pós-processamento dos sinais de tensão e corrente, conforme ilustra a figura 1. Nesta figura os sinais $V(k)$ e $I(k)$ são as amostras instantâneas dos sinais de tensão e corrente fornecidos pelos transformadores de potencial (TP) e de corrente (TC), e não os correspondentes fasores dessas grandezas, como utilizado em alguns dos trabalhos referenciados (Jiali, 1997; Li, 2001; Bouthiba, 2004). Como pode ser observado na figura 1, esses sinais de entrada, após serem préprocessados, são aplicados a duas redes neurais. A primeira é responsável pela estimativa da parte resistiva e a segunda pela estimativa da parte reativa da impedância de falta. Conforme discutido no item 2.1, as estimativas de resistência e reatância são realizadas no sistema por unidade (p.u.), tornase necessário, portanto, a etapa de pós-processamento para transformar esses valores para Ohms.

\section{ELEMENTO DE MEDIÇÃO DE IMPEDÂNCIA BASEADO EM RNA}

Numa linha de transmissão trifásica os possíveis tipos de faltas são: monofásica ( $\mathrm{AN}, \mathrm{BN}$ e $\mathrm{CN})$, dupla-fase $(\mathrm{AB}, \mathrm{BC}$

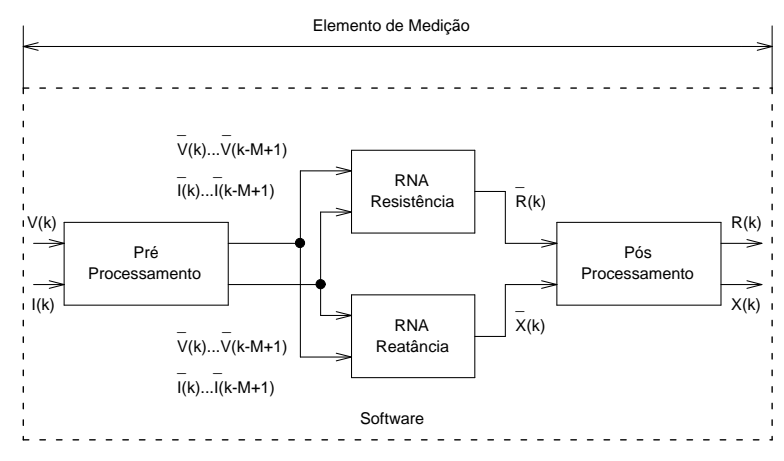

Figura 1: Elemento de medição de impedância (genérico)

e $\mathrm{CA}$ ), dupla-fase e terra (ABN, BCN e CAN), e trifásica $(\mathrm{ABC}$ e $\mathrm{ABCN})$. Como mostrado no Apêndice A, seis equações diferenciais de primeira ordem podem representar todos esses dez tipos de falta numa linha trifásica simplificada (sem as capacitâncias). Todas essas equações relacionam, para cada tipo de falta específico, as correntes e tensões correspondentes com os parâmetros de seqüência positiva da linha (resistência e reatância). Como discutido em detalhes em Santos e Senger (2004), esses resultados mostram que:

a) Para um defeito fase-terra AN os parâmetros da impedância da falta $\left(\mathrm{R}^{1}\right.$ e $\left.\mathrm{L}^{1}\right)$ podem ser obtidos a partir dos sinais $v_{a}, i_{a r}$ e $i_{a x}$. O mesmo raciocínio pode ser aplicado a todos os demais tipos de falta. Isso leva a seis elementos de medição, cada um correspondendo a uma dessas equações diferenciais e com seus respectivos sinais de entrada.

b) Cada uma dessas equações diferenciais pode ser vista como o equacionamento de uma linha monofásica (sem capacitância), cuja impedância série é igual à impedância de seqüência positiva da linha trifásica considerada. Esse resultado é importante por possibilitar o treinamento das RNA a partir de um circuito monofásico, como discutido no item 3.

Dessa forma, para a determinação da impedância da falta, o relé de distância possui seis elementos de medição. Três desses elementos são denominados de elementos de fase (AB, $\mathrm{BC}$ e CA) e cobrem os defeitos que envolvem mais de uma fase. Os outros três elementos, são denominados de elementos de terra (AN, BN e CN) e cobrem os casos de defeitos que envolvem uma fase e a terra. Portanto, com esses seis elementos de medição é possível cobrir os dez tipos de defeitos possíveis numa linha de transmissão trifásica.

\subsection{Etapa de Pré-Processamento}

Na solução proposta a etapa de pré-processamento gera os sinais de entrada para cada um dos seis elementos de medição do relé de distância. Isto significa que esta etapa é responsá- 


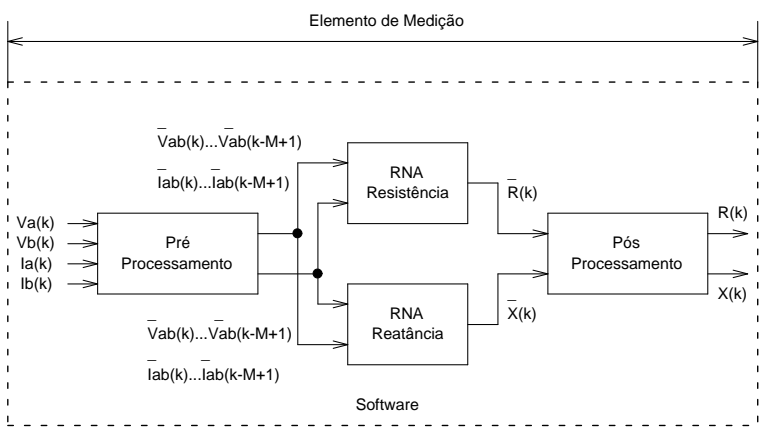

Figura 2: Elemento de fase $\mathrm{AB}$

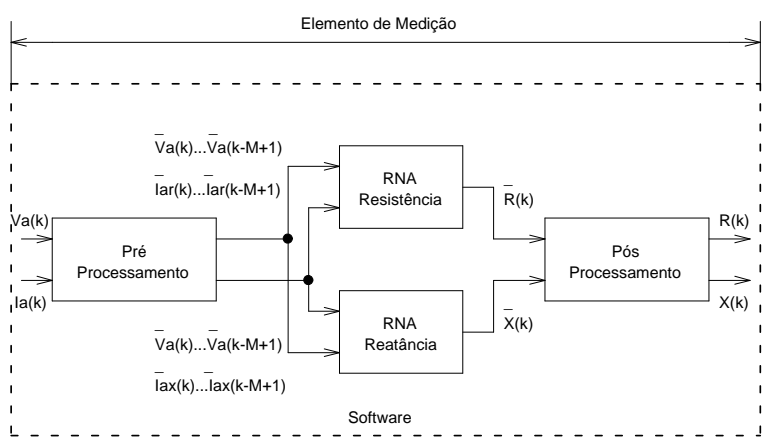

Figura 3: Elemento de terra AN

vel por gerar os vetores de entrada, com os sinais de tensão e corrente adequados, para as duas RNA presentes em cada elemento de medição. Este processo é ilustrado nas figuras 2 e 3, para o elemento de fase $\mathrm{AB}$ e o elemento de terra $\mathrm{AN}$.

Os sinais de entrada para as redes neurais do elemento de fase $\mathrm{AB}$ são gerados através das expressões 1 e 2 , enquanto os sinais de entrada para as redes neurais do elemento de terra AN são gerados através das expressões 3 a 6 . Para os demais elementos de medição, procedimento análogo ao descrito deve ser efetuado, alterando-se apenas os sinais de entrada (tensão de fase e corrente de linha) desses elementos (Santos e Senger, 2004; Blackburn, 1998; Horowitz e Phadke, 1996).

$$
\begin{gathered}
v_{a b(k)}=v_{a(k)}-v_{b(k)} \\
i_{a b(k)}=i_{a(k)}-i_{b(k)} \\
i_{a r(k)}=i_{a(k)}+K r \cdot i^{0}(k) \\
i_{a x(k)}=i_{a(k)}+K x \cdot i^{0}(k) \\
K r=\frac{r^{0}-r^{1}}{r^{1}} \\
K x=\frac{l^{0}-l^{1}}{l^{1}}
\end{gathered}
$$

Os fatores $K r$ e $K x$ nas expressões 3 e 4 são utilizados, quando se trabalha no domínio do tempo, para compensar o efeito da impedância de sequiência zero na corrente de falta (Santos e Senger, 2004). Já $r^{0}, r^{1}, l^{0}$ e $l^{1}$ correspondem, respectivamente, às resistências $(\Omega / \mathrm{km})$ e indutâncias $(\mathrm{H} / \mathrm{km})$ de seqüência zero e positiva da linha de transmissão.

Os valores obtidos nas expressões 1 a 4 formam vetores, compostos por janelas de dados com M amostras de tensão e corrente. Tais vetores são inseridos em RNA previamente treinadas para estimarem os valores de resistência e reatância ( $\mathrm{R} \mathrm{e} \mathrm{X),} \mathrm{conforme} \mathrm{ilustram} \mathrm{as} \mathrm{figuras} 2$ e 3.

Sobre cada janela de dados de tensão e corrente (que formam o vetor de entrada da RNA) é aplicado o sistema por unidade (p.u.), desvinculando o algoritmo proposto do nível de tensão da linha de transmissão e satisfazendo a imposição da função de ativação das RNA, que só admite valores entre -1 e 1 (Tansig - Tangente Hiberbólica), conforme Demuth (1994).

O processo de aplicação do sistema p.u. consta em dividir todos os elementos de uma janela de dados de $\mathrm{M}$ amostras, por seu maior elemento em valor absoluto. Quando esse processo ocorre numa janela de dados de tensão, esse elemento é denominado de tensão de base $(V b)$. Já quando o processo ocorre para numa janela de dados de corrente, o maior elemento da janela é denominado de corrente de base $(I b)$. A exemplo do sistema p.u. convencional, através dos valores de base de tensão e corrente, determina-se o valor da impedância de base $(Z b)$, que neste caso é calculado a cada nova amostra que chega às janelas de dados, conforme a expressão 7. Observa-se, nesta expressão, que todos os valores de base considerados são relativos a amostra mais recente $k$. A impedância de base é utilizada na etapa de pós-processamento do algoritmo.

$$
Z b_{(k)}=\frac{V b_{(k)}}{I b_{(k)}}
$$

Como exemplo, a seguir são apresentas as janelas de dados do vetor de entrada do elemento AB. Notar que $v_{a b}$ e $i_{a b}$ correspondem a uma seqüência de $\mathrm{M}$ amostras provenientes das expressões 1 e 2 . Após tais seqüências serem divididas por seus respectivos valores de base $V b_{a b(k)}$ e $I b_{a b(k)}$ são geradas as janelas de dados em p.u. $\bar{v}_{a b}$ e $\bar{i}_{a b}$, cujo maior valor é \pm 1 .

$$
\begin{gathered}
v_{a b}=\left[\begin{array}{llll}
v_{a b(k)} & v_{a b(k-1)} & \cdots & v_{a b(k-M+1)}
\end{array}\right] \\
i_{a b}=\left[\begin{array}{llll}
i_{a b(k)} & i_{a b(k-1)} & \cdots & i_{a b(k-M+1)}
\end{array}\right] \\
V b_{a b(k)}=\max \left[\left|v_{a b(k)}\right|\left|v_{a b(k-1)}\right|\left|v_{a b(k-2)}\right| \cdots\left|v_{a b(k-M+1)}\right|\right] \\
I b_{a b(k)}=\max \left[\left|i_{a b(k)}\right|\left|i_{a b(k-1)}\right|\left|i_{a b(k-2)}\right| \cdots\left|i_{a b(k-M+1)}\right|\right]
\end{gathered}
$$




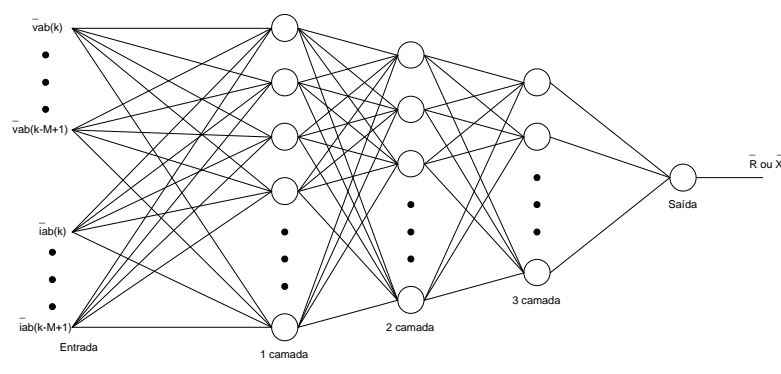

Figura 4: Rede $\mathrm{R}$ e $\mathrm{X}$ do elemento de fase $\mathrm{AB}$

$$
\begin{gathered}
\bar{v}_{a b}=\frac{v_{a b}}{V b_{a b(k)}}=\left[\begin{array}{lll}
\bar{v}_{a b(k)} & \bar{v}_{a b(k-1)} \cdots \bar{v}_{a b(k-M+1)}
\end{array}\right] \\
\bar{i}_{a b}=\frac{i_{a b}}{I b_{a b(k)}}=\left[\begin{array}{lll}
\bar{i}_{a b(k)} & \bar{i}_{a b(k-1)} \cdots \bar{i}_{a b(k-M+1)}
\end{array}\right]
\end{gathered}
$$

\subsection{Etapa das RNA}

A etapa das RNA é o núcleo do algoritmo desenvolvido e consta, basicamente, de redes previamente treinadas para aproximar funções. Neste algoritmo são utilizados dois tipos de redes neurais: a primeira treinada para determinar o valor da resistência (rede R); a segunda treinada para determinar o valor de reatância (rede X). Estas duas redes determinam esses valores a partir das amostras de tensão e corrente, aplicadas nas suas entradas, por intermédio dos seus respectivos vetores de entrada. Tanto os valores de entrada, como os valores de saída da rede neural, encontram-se no sistema p.u..

A figura 4 apresenta a RNA utilizada para processar o vetor de entrada do elemento de medição $\mathrm{AB}$, supondo janelas de dados com $\mathrm{M}$ amostras de tensão e corrente.

\subsection{Etapa de Pós-Processamento}

Esta etapa transforma em Ohms, os valores de resistência e reatância (em p.u.) presentes nas saídas das RNA. Essa transformação consiste em multiplicar a saída da rede pelo valor de impedância de base $(Z b)$, calculado, a cada nova amostra, conforme a expressão 7. A partir dos valores de resistência e reatância em Ohms e da característica de atuação ajustada para o elemento de fase 21 ou para o elemento de terra $21 \mathrm{~N}$, o relé pode gerar ou não o sinal de trip, isolando o trecho faltoso da linha de transmissão. A figura 5 apresenta um diagrama exemplificando o processo de pós-processamento.

Este procedimento é similar à obtenção dos valores em Ohms quando se trabalha com o sistema p.u. convencional, a menos de que, neste caso, os valores de base e, portanto, em Ohms são recalculados a cada nova amostra que entra nas janelas de dados de tensão e corrente. Sendo assim, o processo apresentado pode ser entendido como um sistema p.u.

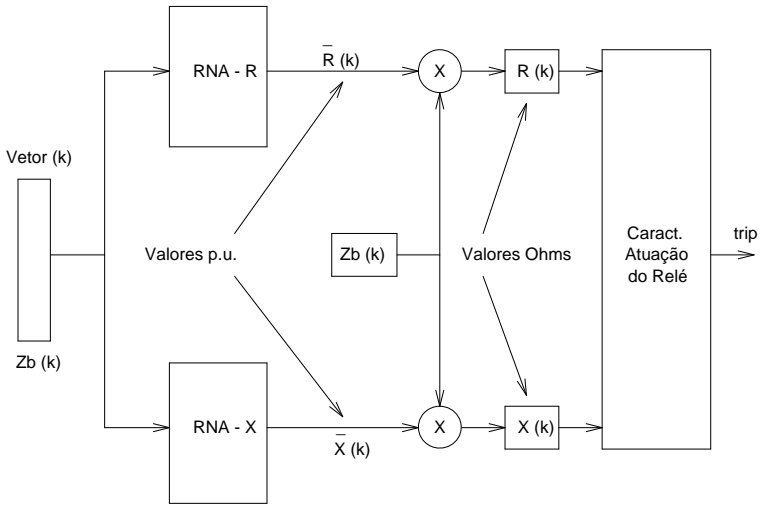

Figura 5: Etapa de Pós-Processamento

"dinâmico".

\section{TREINAMENTO DAS RNA}

Para o algoritmo proposto são necessárias duas categorias de RNA: uma que estima o valor de resistência (em p.u.) e outra que estima o valor de reatância (em p.u.), a partir de amostras de tensão e corrente (em p.u.) contidas nos seus vetores de entrada. Portanto, devem existir dois conjuntos de treinamento, um para treinar a rede $\mathrm{R}$ e outro para treinar a rede $\mathrm{X}$.

Nesta pesquisa optou-se pela utilização de redes MLP (próprias para a aproximação de funções), treinamento supervisionado (para cada vetor de entrada é apresentado o vetor de saída desejado) e algoritmo de aprendizado Backpropagation (Demuth, 1994; Wasserman, 1989).

\subsection{Metodologia Utilizando Modelo Monofásico de $1^{a}$ Ordem}

É importante ressaltar que a utilização de um modelo monofásico de primeira ordem para o treinamento das RNA é possível devido ao esquema de pré-processamento adotado para o algoritmo, pois este resulta em equações envolvendo somente os parâmetros de sequiência positiva da linha (R1 e X1), conforme mostrado no Apêndice A e detalhado por Santos e Senger (2004). Este fato proporciona que as RNA que atuarão numa linha de transmissão trifásica sejam treinadas através de sinais provenientes do circuito apresentado na figura 6 . Tal possibilidade simplifica e agiliza significativamente o processo de treinamento das RNA, uma vez que evita a necessidade de modelagem do sistema trifásico completo para gerar os sinais de treinamento. Por outro lado, convém ressaltar que o referido modelo não contempla a situação de ondas trafegantes, comum em linhas longas com 
A

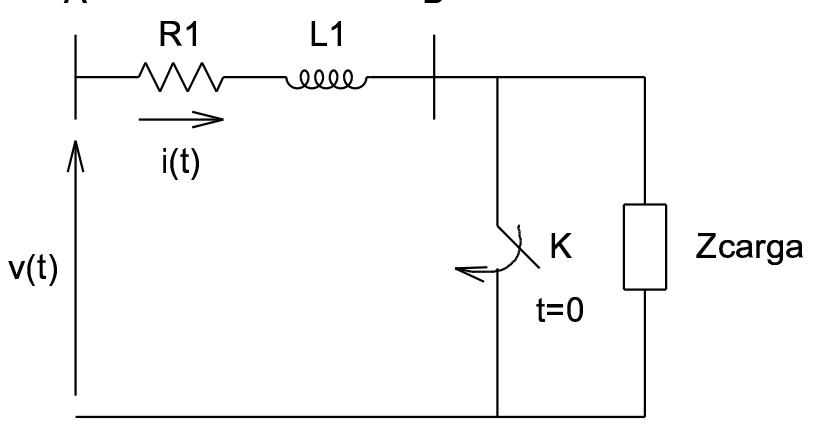

Figura 6: Sistema monofásico de primeira ordem

níveis de tensão elevados. A influência dessa restrição no desempenho das RNA operando num sistema trifásico real é discutida nos itens seguintes.

O sistema monofásico de primeira ordem utilizado para gerar os sinais de treinamento das RNA é mostrado na figura 6. Esse sistema consta da tensão da barra A alimentando uma carga através de uma resistência e uma indutância, representando a impedância série de sequiência positiva de uma linha de transmissão. A condição de falta é simulada através do fechamento de uma chave $\mathrm{K}$ no instante $\mathrm{t}=0$.

Os sinais referentes às possíveis condições operativas dessa linha de transmissão, nas condições de pré-falta (expressões 8 e 9) e falta (expressões 8 e 10), considerando $I_{\text {falta }}>>$ $I_{\text {carga }}$, são:

$$
\begin{gathered}
v=V \cdot \cos (w \cdot t+\theta) \\
i=I_{\text {carga }} \cdot \cos (w \cdot t+\theta-\phi) \\
i=I_{\text {falta }} \cdot\left[-\cos (\theta-\beta) \cdot e^{-\alpha \cdot t}+\cos (w \cdot t+\theta-\beta)\right]
\end{gathered}
$$

onde,

$\phi=$ Fator de potência do conjunto carga mais linha;

$\theta=$ Ângulo da tensão que ocorre a falta;

$\alpha=$ inverso da cte de tempo do sistema de primeira ordem.

$\beta=\operatorname{arctag}(w \mathrm{~L} 1 / \mathrm{R} 1)$.

As expressões 11 e 12 representam o valor da impedância medida por um relé de distância instalado na barra A, para as situações de pré-falta e falta, respectivamente:

$$
\begin{aligned}
& Z_{\text {relé }}=\frac{V}{I_{\text {carga }}}[\cos (\phi)+j \cdot \operatorname{sen}(\phi)] \\
& Z_{\text {relé }}=\frac{V}{I_{\text {falta }}}[\cos (\beta)+j \cdot \operatorname{sen}(\beta)]
\end{aligned}
$$

A partir das expressões 8 a 12, e admitindo-se uma taxa de amostragem de $N$ amostras por ciclo de $60 \mathrm{~Hz}$ e janelas de dados com $M$ amostras dos sinais de tensão e corrente, temse na situação de pré-falta as expressões 13 e 14, e na situação de falta as expressões 13 e 15 .

$$
\begin{gathered}
\left\{v_{k}\right\}=V \cdot \cos \left(\frac{2 \cdot \pi}{N} \cdot k+\theta\right) \\
\left\{i_{k}\right\}=I_{\text {carga }} \cdot \cos \left(\frac{2 \cdot \pi}{N} \cdot k+\theta-\phi\right) \\
\left\{i_{k}\right\}=I_{\text {falta }} \cdot\left[-\cos (\theta-\beta) \cdot e^{-\alpha \cdot k \cdot \frac{T}{N}}+\cos \left(\frac{2 \cdot \pi}{N} \cdot k+\theta-\beta\right)\right]
\end{gathered}
$$

onde: $k=0 \ldots M-1$ (tamanho da janela de dados).

As seqüências de amostras $v_{k}$ e $i_{k}$ devem ser submetidas ao processo p.u., conforme discutido no item 2.1. Dessa forma:

$$
\begin{array}{r}
\left\{\bar{v}_{k}\right\}=\frac{\left\{v_{k}\right\}}{V b} \\
\left\{\bar{i}_{k}\right\}=\frac{\left\{i_{k}\right\}}{I b}
\end{array}
$$

sendo,

$$
\begin{gathered}
V b=\max \left\{\left|v_{k}\right|\right\} \\
I b=\max \left\{\left|i_{k}\right|\right\} \\
Z b=\frac{V b}{I b}
\end{gathered}
$$

Portanto, após a aplicação do sistema p.u., a situação de préfalta é representada pelas expressões 21,22 e 24 , e a situação de falta passa a ser representada pelas expressões 21,23 e 25 .

$$
\begin{gathered}
\left\{\bar{v}_{k}\right\}=\frac{V \cdot \cos \left(\frac{2 \cdot \pi}{N} \cdot k+\theta\right)}{V b} \\
\left\{\bar{i}_{k}\right\}=\frac{I_{\text {carga }} \cdot \cos \left(\frac{2 \cdot \pi}{N} \cdot k+\theta-\phi\right)}{I b} \\
\left\{\bar{i}_{k}\right\}=\frac{I_{\text {falta }} \cdot\left[-\cos (\theta-\beta) \cdot e^{-\alpha \cdot k \cdot \frac{T}{N}}+\cos \left(\frac{2 \cdot \pi}{N} \cdot k+\theta-\beta\right)\right]}{I b} \\
\bar{Z}_{\text {relé }}=\frac{V}{I_{\text {carga }} \cdot Z_{\text {base }}} \cdot[\cos (\phi)+j \cdot \operatorname{sen}(\phi)] \\
\bar{Z}_{\text {relé }}=\frac{V}{I_{\text {falta }} \cdot Z_{\text {base }}} \cdot[\cos (\beta)+j \cdot \operatorname{sen}(\beta)]
\end{gathered}
$$

Conforme discutido na etapa de pré-processamento (item 2.1) os vetores de entrada das RNA devem estar no sistema p.u.. Tal fato torna desnecessário o treinamento das RNA para todas as amplitudes possíveis de tensão e corrente das diversas linhas de transmissão existentes. Assim, por exemplo, um sinal com amplitude de $10 \mathrm{~V}$ gera os mesmos vetores 
de treinamento (em p.u.) que um sinal com amplitude de 20 V. Isso ocorre porque neste último caso o valor da tensão de base $(V b)$, numa dada janela de dados, é o dobro do $V b$ do primeiro caso. Sendo assim, constata-se que a partir do método adotado, o treinamento independe da amplitude dos sinais de tensão e corrente, que, portanto, podem ser unitários, isto é: $V=1,0 \mathrm{~V} ; I_{\text {carga }}=1,0 \mathrm{~A} ; I_{\text {falta }}=1,0 \mathrm{~A}$. Admitindose os sinais de tensão e corrente unitários, as expressões 26 , 27,29 e 30 geram os vetores de treinamento referentes as situações de pré-falta, enquanto as expressões $26,28,31$ e 32 , geram os vetores de treinamento referentes as situações de falta. Tais vetores são utilizados para treinar uma RNA capaz de responder a sinais de tensão e corrente provenientes de qualquer linha de transmissão, independentemente do nível de tensão, comprimento ou geometria da mesma.

$$
\begin{aligned}
&\left\{\bar{v}_{k}\right\}=\frac{\cos \left(\frac{2 \cdot \pi}{N} \cdot k+\theta\right)}{V b} \\
&\left\{\bar{i}_{k}\right\}= \frac{\cos \left(\frac{2 \cdot \pi}{N} \cdot k+\theta-\phi\right)}{I b} \\
&\left\{\bar{i}_{k}\right\}=\frac{\left[-\cos (\theta-\beta) \cdot e^{-\alpha \cdot k \cdot \frac{T}{N}}+\cos \left(\frac{2 \cdot \pi}{N} \cdot k+\theta-\beta\right)\right]}{I b} \\
& \bar{R}=\frac{\cos (\phi)}{Z b} \\
& \bar{X}=\frac{\operatorname{sen}(\phi)}{Z b} \\
& \bar{R}=\frac{\cos (\beta)}{Z b} \\
& \bar{X}=\frac{\operatorname{sen}(\beta)}{Z b}
\end{aligned}
$$

A rotina (desenvolvida em linguagem Matlab) que executa as expressões, 26 a 32, é dividida em duas etapas, que são: geração das situações operativas para o treinamento em regime permanente (pré-falta); geração das situações operativas para o treinamento com componente exponencial (falta). No primeiro caso, os valores de $\theta$ e $\phi$ são sorteados numa faixa de 0 a $2 . \pi$, representando qualquer possibilidade de fator de potência e ângulo de tensão, contemplando todos os estados de operação do sistema em regime permanente. Já no segundo caso, os valores de $\beta$ e $\theta$ são sorteados numa faixa limitada pelo período transitório do defeito, ou seja, quando $\theta$ encontra-se entre 0 e $2 . \pi$, representando qualquer ângulo de tensão para a ocorrência do defeito e $\beta$ entre $-\pi / 6$ e $-\pi$, representando a defasagem entre a tensão e a corrente durante o curto-circuito. Os valores de $\alpha$ são sorteados numa faixa de 20 a 100, representando o inverso das constantes de tempo das linhas de transmissão nos diversos níveis de tensões adotados na prática. $\mathrm{O}$ sorteio das variáveis $\theta, \phi, \beta$ e $\alpha$, nas faixas apresentadas, impede que sejam gerados vetores que representam situações irreais, ou seja, não plausíveis na prática.

Após S situações simuladas obtêm-se dois conjuntos de treinamento: um para a rede $\mathrm{R}$, com $\mathrm{S}$ vetores de entrada (formados por $\left\{\bar{v}_{k}\right\}$ e $\left\{\bar{i}_{k}\right\}$ ) associados a $\mathrm{S}$ valores de $\mathrm{R}$ (expressões 29 e 31); e um para a rede $X$, com os mesmos $S$ vetores de entrada associados a $\mathrm{S}$ valores de $\mathrm{X}$ (expressões 30 e 32).

\subsection{Arquitetura das RNA e Parâmetros de Treinamento}

Neste trabalho várias configurações de RNA e parâmetros de treinamento foram testados, frente aos conjuntos de treinamento gerados no item anterior. Na configuração final, os parâmetros de treinamento mais relevantes são:

- Momentum = 0,9

- Taxa de Aprendizado = 0,01

- Erro desejado = 1.10-9

- Número máximo de iterações $=500.000$

- Algoritmo de aprendizado = Backpropagation

- Função de transferência de todos os neurônios = Tansig

Para a implementação das RNA foi utilizado o software Matlab (Neural Network Toolbox). O treinamento destas redes foi realizado mediante 4500 vetores de entrada/saída, provenientes das expressões (26 a 32) representativas das janelas de dados de tensão e corrente do modelo monofásico de primeira ordem apresentado na figura 6 .

Durante a fase de definição da arquitetura das RNA (R e X), foram avaliadas redes com diversos tamanhos de janelas de dados e taxas de amostragem. Os resultados alcançados no treinamento dessas redes são apresentados em Santos e Senger (2004) e indicam, após uma análise detalhada, que redes com janela de dados de 16 amostras e taxas de amostragem de 32 amostras por ciclo $(60 \mathrm{~Hz})$ são mais apropriadas para a implementação do algoritmo proposto. Tais redes receberam as denominações Rede-32-16-r e Rede-32-16-x em função da taxa de amostragem e da janela de dados utilizadas, além do tipo de resposta emitida por cada uma delas - resistência (r) ou reatância (x). Ambas as redes possuem quatro camadas com: 32 neurônios de entrada; 65 e 8 neurônios nas camadas ocultas e 1 neurônio na camada de saída. No processo de treinamento a Rede-32-16-r atingiu um erro de 6,42.10 ${ }^{-5}$ e a Rede-32-16-x atingiu um erro de $2,95 \cdot 10^{-5}$. Um estudo detalhado sobre o treinamento e testes de todas as arquiteturas avaliadas durante a fase de concepção das RNA é apresentado na referência citada neste parágrafo. 


\subsection{Validação das RNA}

Para a avaliação das RNA frente a sinais não pertencentes aos seus conjuntos de treinamento, são gerados sinais aleatórios representativos das condições de pré-falta e falta de uma linha de transmissão monofásica. Estes sinais (já no sistema p.u.), no formato de janela de dados de tensão e corrente, com número de amostras e taxas de amostragem adequadas, conforme as expressões 26 a 32, são agrupados para formar os vetores de entrada das RNA. Para cada vetor de entrada, os valores de resistência e reatância são previamente calculados, possibilitando a comparação entre estes e os valores de resistência e reatância emitidos pelas RNA. É importante ressaltar que nesta primeira etapa de validação os sinais gerados são baseados num sistema de primeira ordem (figura 6), não contemplando, portanto, as situações de ondas trafegantes. Os resultados da validação das redes $\mathrm{R}$ e X são apresentados na tabela 1 .

É importante destacar que cada rede foi submetida a 1500 casos de pré-falta e 1500 casos de falta. Na tabela 1 o número em destaque representa os casos que a RNA calculou a sua saída ( $\mathrm{R}$ ou $\mathrm{X}$ ) com um erro absoluto inferior a 3\%, sendo nos demais casos registrado um erro absoluto entre $3 \%$ e $5 \%$.

Ressalta-se nesta avaliação um fato de extrema relevância, que corresponde à capacidade das RNA filtrarem a componente exponencial (casos de falta), respondendo corretamente quando há ou não componente aperiódica no sinal de entrada.

Tabela 1: Resultado da Validação das RNA

\begin{tabular}{|c|c|c|c|}
\hline \multicolumn{2}{|c|}{ Erro Absoluto $(\varepsilon)$} & Rede-32-16-r & Rede-32-16-x \\
\hline Casos de & $\varepsilon<3 \%$ & $\mathbf{1 3 6 4}$ & $\mathbf{1 3 5 6}$ \\
\cline { 2 - 4 } Pré-falta & $3 \%<\varepsilon<5 \%$ & 136 & 144 \\
\hline Casos de & $\varepsilon<3 \%$ & $\mathbf{1 0 4 7}$ & $\mathbf{1 3 0 1}$ \\
\cline { 2 - 4 } Falta & $3 \%<\varepsilon<5 \%$ & 453 & 199 \\
\hline
\end{tabular}

\section{RESULTADOS DO ALGORITMO BASEADO EM RNA}

Para avaliar o algoritmo proposto, apresentado genericamente na figura 1, este será implementado com as duas RNA validadas; Rede-32-16-r e Rede-32-16-x. Como foi observado, tais redes foram treinadas com sinais provenientes de uma linha monofásica, representada através de um modelo de primeira ordem. Dessa forma, resta avaliar as referidas redes frente às condições reais de operação de uma linha de transmissão trifásica, possibilitando, inclusive, constatar a reação dessas redes frente às situações de defeito que resultam em ondas trafegantes, situações estas não contempladas no processo de treinamento das RNA. Tal avaliação será realizada considerando os tempos de resposta do algoritmo, ou seja, os tempos de trip (Ttrip) e estabilização (Testab) do mesmo.

As linhas utilizadas para avaliar o algoritmo são típicas do sistema brasileiro nos níveis de $138 \mathrm{kV}, 230 \mathrm{kV}, 345 \mathrm{kV}$, $500 \mathrm{kV}$ e $765 \mathrm{kV}$, e possuem comprimento e carregamento compatíveis com esses níveis.

As situações operativas das linhas de transmissão adotadas foram geradas através do Simulink (Power System Toolbox), considerando as seguintes variações: tipo de defeito (faseterra, dupla-fase, dupla-fase-terra e trifásico); distância do defeito $(20 \%, 50 \%$ e $80 \%$ do comprimento da linha de transmissão); resistência de falta $(0 \Omega, 10 \Omega$ e $20 \Omega)$; impedância do equivalente no terminal do relé $(30 \%, 100 \%$ e $120 \%$ do valor real); ângulo da tensão no instante do defeito $\left(0^{\circ}, 45^{\circ}\right.$ e $\left.90^{\circ}\right)$; nível de tensão $(138 \mathrm{kV}, 230 \mathrm{kV}, 345 \mathrm{kV}, 500 \mathrm{kV}$ e $765 \mathrm{kV})$.

Após o algoritmo ser submetido à 12 situações operativas diferentes em cada nível de tensão considerado, a qualidade da resposta emitida por este é medida segundo dois indicadores principais:

Ttrip: Tempo para o algoritmo gerar três respostas consecutivas no interior da primeira zona de proteção do relé (Mho), ajustada para $85 \%$ da linha de transmissão.

Testab: Tempo para o algoritmo emitir respostas sucessivas com um erro menor do que $5 \%$, com relação ao valor correto $\left(\mathrm{Z}_{\text {cor }}\right)$ da impedância de falta. Matematicamente, o Testab é definido segundo a expressão 33.

$$
\frac{\left|Z(t)-Z_{\text {cor }}\right|}{\left|Z_{\text {cor }}\right|}<0,05 \quad \text { para } t>\text { Testab }
$$

A tabela 2 apresenta os tempos médios de trip e estabilização do algoritmo, frente a 12 situações operativas distintas, em cada nível de tensão considerado.

Tabela 2: Tempo médio de estabilização e trip (ms)

\begin{tabular}{|c|c|c|}
\hline Tensão (kV) & Testab & Trip \\
\hline $\mathbf{1 3 8}$ & 12,70 & 8,72 \\
\hline $\mathbf{2 3 0}$ & 15,91 & 8,54 \\
\hline $\mathbf{3 4 5}$ & 17,00 & 10,55 \\
\hline $\mathbf{5 0 0}$ & 35,08 & 7,63 \\
\hline $\mathbf{7 6 5}$ & 39,25 & 8,04 \\
\hline Tempo médio & 23,99 & 8,69 \\
\hline
\end{tabular}

A título de exemplo as figuras 7, 8 e 9 apresentam, no plano R-X, a impedância calculada pelos elementos de medição do 

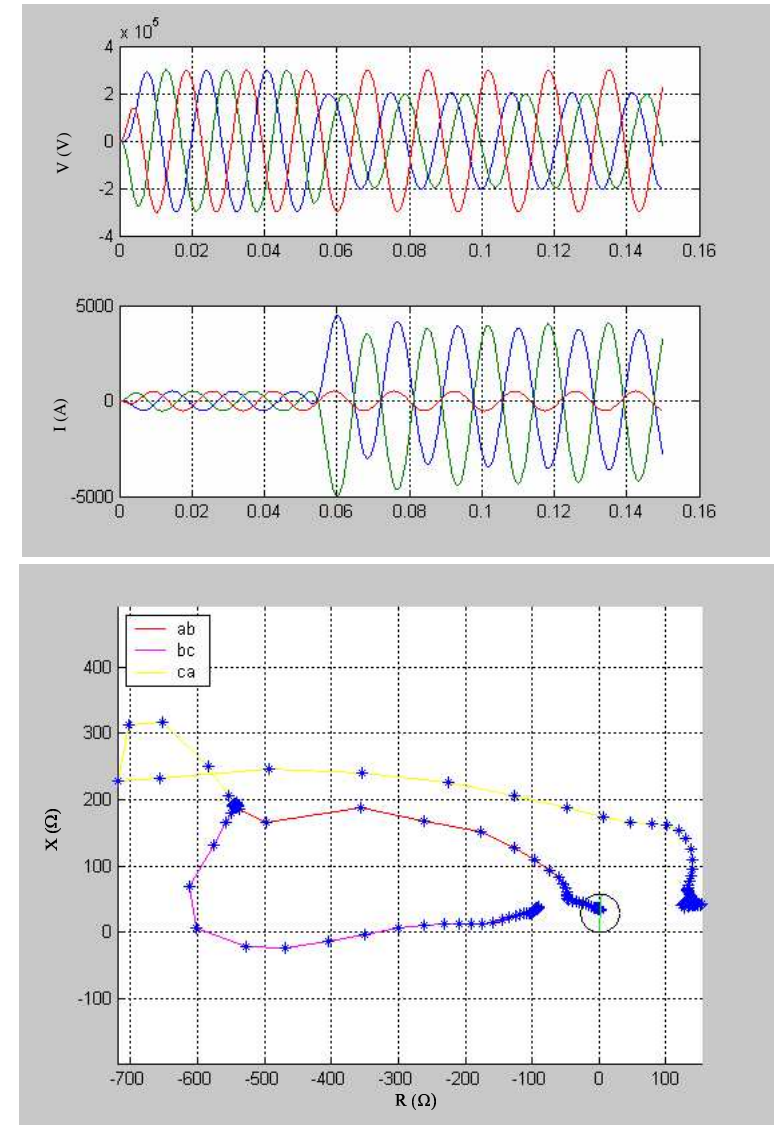

Figura 7: Comportamento dos elementos de fase do algoritmo $-345 \mathrm{kV}$

algoritmo proposto, frente a defeitos numa linha de transmissão de $345 \mathrm{kV}$ e $145 \mathrm{~km}$. Nos três casos apresentados o defeito ocorre no meio da linha de transmissão e o ângulo da tensão é de $45^{\circ}$. No primeiro caso, figura 7 , os sinais Trip e Testab foram gerados, respectivamente, após 12,0 ms e 14,0 $\mathrm{ms}$, para um defeito sólido entre as fases A e B. No segundo caso, figura 8, os sinais Trip e Testab foram gerados, respectivamente, após 9,5 ms e 13,5 ms, para um defeito monofásico (fase A) com resistência de falta de $10 \Omega$. Já no terceiro caso, figura 9, os sinais Trip e Testab foram gerados, respectivamente, após $8,0 \mathrm{~ms}$ e 13,5 ms, para um defeito trifásico sólido.

O sistema de $345 \mathrm{kV}$ simulado e a torre utilizada na sua modelagem são apresentados, respectivamente, nas figuras $10 \mathrm{e}$ 11. As características dos demais sistemas elétricos utilizados $-138 \mathrm{kV}, 230 \mathrm{kV}, 500 \mathrm{kV}$ e $765 \mathrm{kV}$ (parâmetros de linha, geometria das torres, comprimentos das linhas de transmissão, etc), são apresentados em Santos e Senger (2004).

Nas figuras 7, 8 e 9, além dos sinais de tensão e corrente de defeito, referentes a cada situação operativa simulada, é pos-
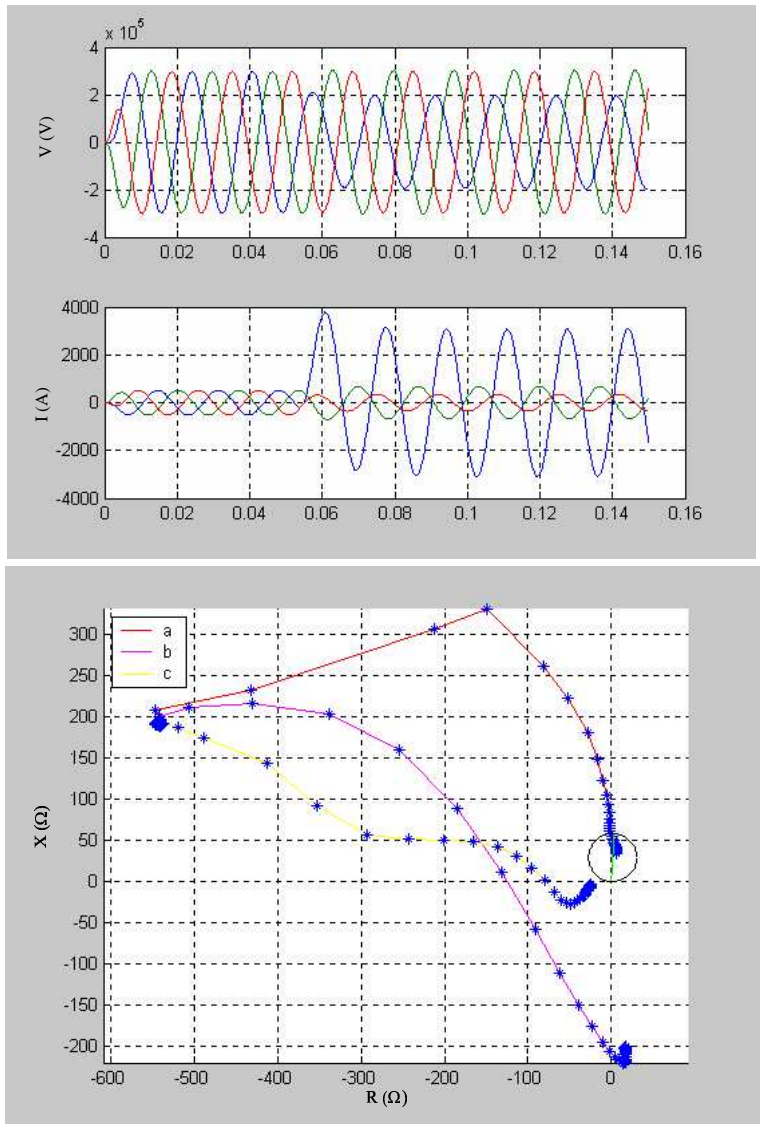

Figura 8: Comportamento dos elementos de terra do algoritmo $-345 \mathrm{kV}$

sível visualizar o comportamento dos elementos de medição do algoritmo. No caso do defeito bifásico (figura 7) somente o elemento de fase $\mathrm{AB}$ penetrou a zona de proteção do relé, enquanto que no caso do defeito trifásico (figura 9) todos os três elementos de fase penetraram a zona de proteção do relé. Já no caso do defeito monofásico (figura 8), somente o elemento de terra AN penetrou a zona de proteção do relé. Tal observação confirma que os esquemas propostos de préprocessamento, RNA e pós-processamento desempenharam a função desejada, visto que em todos os casos os elementos de medição calcularam, com precisão menor do que 5\%, a impedância do defeito.

A torre apresentada na figura 11 é composta por um circuito simples com dois condutores por fase, flecha de 7,80 metros e condutor tipo (Bluebird) ACSR 2156 MCM (84/19). Já o pára-raios possui flecha de 4,70 metros e diâmetro de 7/16" (HS). 


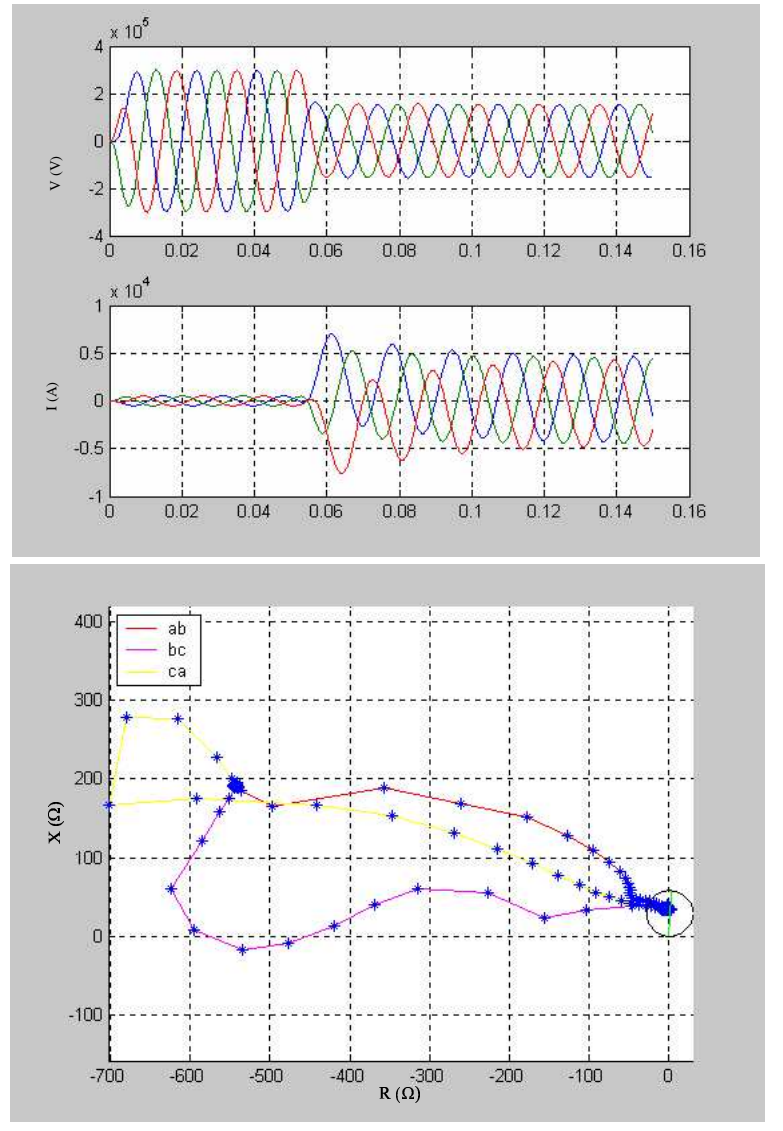

Figura 9: Comportamento dos elementos de fase do algoritmo $-345 \mathrm{kV}$

\section{L.T. $345 \mathrm{kV}$}

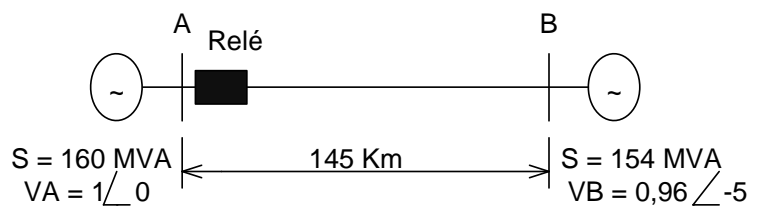

Figura 10: Sistema de $345 \mathrm{kV}$ utilizado na simulação

\section{COMPARAÇÃO ENTRE OS ALGORITMOS: RNA X FOURIER}

Para mensurar a aplicabilidade do algoritmo proposto, este terá seu desempenho comparado com o desempenho de um algoritmo convencional utilizado na proteção de distância Algoritmo de Fourier (Blackburn, 1998; Horowitz e Phadke, 1996; Senger e Santana, 1998). Esta comparação consta da análise das respostas de cada um desses algoritmos, frente a 480 simulações de possíveis condições operativas das linhas

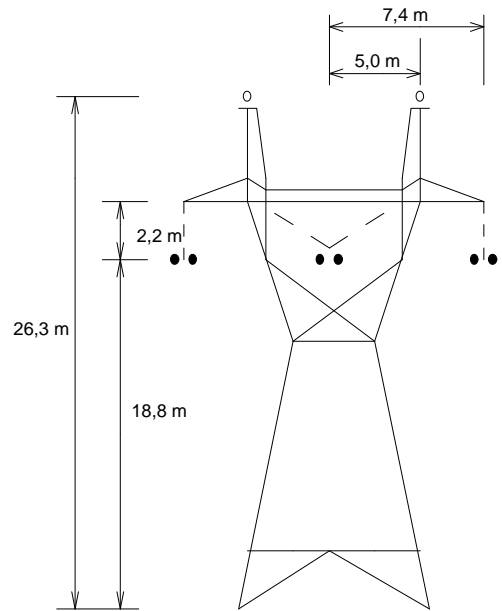

Figura 11: Torre utilizada na modelagem do sistema de 345 $\mathrm{kV}$

de transmissão consideradas no presente estudo. Tais condições operativas correspondem a 32 variações nos parâmetros de simulação do sistema elétrico (instante do defeito, tipo de defeito, resistência de falta, etc), além de três comprimentos diferentes de linha de transmissão, em cada nível de tensão considerado ( 32 casos x 3 comprimentos x 5 níveis). A variação no comprimento das linhas de transmissão visa medir o comportamento do algoritmo proposto diante de linhas curtas, médias e longas.

As tabelas 3 e 4 apresentam os tempos médios de trip e estabilização dos algoritmos em teste nas seguintes condições: 32 casos simulados em cada um dos três comprimentos adotados para cada nível de tensão. O número entre parênteses representa a quantidade de vezes que o algoritmo desenvolvido respondeu mais rápido do que o algoritmo convencional.

Com relação a tabela 3, constata-se que o algoritmo baseado em RNA possui melhor desempenho do que o algoritmo convencional, pois independentemente da linha de transmissão e do comprimento desta, o algoritmo desenvolvido possui tempos médios de trip significativamente mais baixos. Já com relação a tabela 4, constata-se que até o nível de $345 \mathrm{kV}$ o algoritmo baseado em RNA apresenta um desempenho ligeiramente superior ao algoritmo convencional. Entretanto, acima desse nível, o algoritmo de Fourier mostra-se mais adequado do que o baseado em RNA, que tem seu desempenho comprometido devido ao efeito das ondas trafegantes, presentes nas linhas mais longas. Tal limitação existe porque o treinamento das redes $\mathrm{R}$ e $\mathrm{X}$ do algoritmo foi realizado a partir de um modelo de primeira ordem (figura 6), que não contempla 
Tabela 3: Tempo médio de trip (ms)

\begin{tabular}{|c|c|c|c|c|}
\hline Nível & Algoritmo & $\mathbf{5 0} \mathbf{~ k m}$ & $\mathbf{7 4} \mathbf{~ k m}$ & $\mathbf{1 5 0} \mathbf{~ k m}$ \\
\hline \multirow{2}{*}{$\mathbf{1 3 8 k V}$} & \multirow{2}{*}{ RNA } & $\begin{array}{c}06,88 \\
(97 \%)\end{array}$ & $\begin{array}{c}08,16 \\
(100 \%)\end{array}$ & $\begin{array}{c}06,90 \\
(100 \%)\end{array}$ \\
\hline & Fourier & 14,20 & 15,63 & 13,7 \\
\hline & & $\mathbf{8 0} \mathbf{~ k m}$ & $\mathbf{1 0 0} \mathbf{~ k m}$ & $\mathbf{2 0 0} \mathbf{~ k m}$ \\
\hline \multirow{2}{*}{$\mathbf{2 3 0 k V}$} & \multirow{2}{*}{ RNA } & $\begin{array}{c}09,00 \\
(93 \%)\end{array}$ & $\begin{array}{c}08,83 \\
(93 \%)\end{array}$ & $\begin{array}{c}07,90 \\
(87 \%)\end{array}$ \\
\hline & Fourier & 13,30 & 13,03 & 12,67 \\
\hline & & $\mathbf{1 0 0} \mathbf{~ k m}$ & $\mathbf{1 4 5} \mathbf{~ k m}$ & $\mathbf{3 0 0} \mathbf{~ k m}$ \\
\hline \multirow{2}{*}{$\mathbf{3 4 5 k V}$} & \multirow{2}{*}{ RNA } & $\begin{array}{c}11,40 \\
(100 \%)\end{array}$ & $\begin{array}{c}10,55 \\
(100 \%)\end{array}$ & $\begin{array}{c}09,75 \\
(100 \%)\end{array}$ \\
\hline & Fourier & 16,70 & 16,20 & 15,40 \\
\hline & & $\mathbf{1 8 1} \mathbf{~ k m}$ & $\mathbf{3 0 0} \mathbf{~ k m}$ & $\mathbf{4 0 0} \mathbf{~ k m}$ \\
\hline \multirow{2}{*}{$\mathbf{5 0 0 k V}$} & \multirow{2}{*}{ RNA } & $\begin{array}{c}07,60 \\
(97 \%)\end{array}$ & $\begin{array}{c}06,77 \\
(97 \%)\end{array}$ & $\begin{array}{c}06,17 \\
(97 \%)\end{array}$ \\
\hline & Fourier & 13,06 & 12,43 & 12,56 \\
\hline & & $\mathbf{2 6 5} \mathbf{~ k m}$ & $\mathbf{3 5 0} \mathbf{~ k m}$ & $\mathbf{5 0 0} \mathbf{~ k m}$ \\
\hline \multirow{2}{*}{$\mathbf{2 6 5 k V}$} & RNA & $\begin{array}{c}07,01 \\
(100 \%)\end{array}$ & $\begin{array}{c}06,75 \\
(97 \%)\end{array}$ & $\begin{array}{c}07,40 \\
(87 \%)\end{array}$ \\
\hline & Fourier & 13,46 & 13,10 & 12,93 \\
\hline
\end{tabular}

Tabela 4: Tempo médio de estabilização (ms)

\begin{tabular}{|c|c|c|c|c|}
\hline Nível & Algoritmo & $\mathbf{5 0} \mathbf{~ k m}$ & $\mathbf{7 4} \mathbf{~ k m}$ & $\mathbf{1 5 0} \mathbf{~ k m}$ \\
\hline \multirow{2}{*}{$\mathbf{1 3 8 k V}$} & \multirow{2}{*}{ RNA } & $\begin{array}{c}12,28 \\
(94 \%)\end{array}$ & $\begin{array}{c}13,65 \\
(97 \%)\end{array}$ & $\begin{array}{c}12,17 \\
(100 \%)\end{array}$ \\
\hline & Fourier & 17,97 & 18,75 & 18,12 \\
\hline & & $\mathbf{8 0} \mathbf{~ k m}$ & $\mathbf{1 0 0} \mathbf{~ k m}$ & $\mathbf{2 0 0} \mathbf{~ k m}$ \\
\hline \multirow{2}{*}{$\mathbf{2 3 0 k V}$} & \multirow{2}{*}{ RNA } & $\begin{array}{c}17,28 \\
(72 \%)\end{array}$ & $\begin{array}{c}17,04 \\
(72 \%)\end{array}$ & $\begin{array}{c}14,05 \\
(88 \%)\end{array}$ \\
\hline & Fourier & 17,22 & 17,18 & 17,59 \\
\hline & & $\mathbf{1 0 0} \mathbf{~ k m}$ & $\mathbf{1 4 5} \mathbf{~ k m}$ & $\mathbf{3 0 0} \mathbf{~ k m}$ \\
\hline \multirow{2}{*}{$\mathbf{3 4 5 k V}$} & \multirow{2}{*}{ RNA } & $\begin{array}{c}17,15 \\
(75 \%)\end{array}$ & $\begin{array}{c}17,57 \\
(69 \%)\end{array}$ & $\begin{array}{c}18,46 \\
(72 \%)\end{array}$ \\
\hline & Fourier & 19,50 & 18,30 & 18,53 \\
\hline & & $\mathbf{1 8 1} \mathbf{~ k m}$ & $\mathbf{3 0 0} \mathbf{~ k m}$ & $\mathbf{4 0 0} \mathbf{~ k m}$ \\
\hline \multirow{2}{*}{$\mathbf{5 0 0 k V}$} & RNA & $\begin{array}{c}36,85 \\
(41 \%)\end{array}$ & $\begin{array}{c}35,03 \\
(47 \%)\end{array}$ & $\begin{array}{c}44,42 \\
(38 \%)\end{array}$ \\
\hline & Fourier & 16,93 & 17,00 & 16,93 \\
\hline & & $\mathbf{2 6 5} \mathbf{~ k m}$ & $\mathbf{3 5 0} \mathbf{~ k m}$ & $\mathbf{5 0 0} \mathbf{~ k m}$ \\
\hline \multirow{2}{*}{$\mathbf{7 6 5 k V}$} & RNA & $\begin{array}{c}36,70 \\
(41 \%)\end{array}$ & $\begin{array}{c}35,54 \\
(38 \%)\end{array}$ & $\begin{array}{c}41,48 \\
(44 \%)\end{array}$ \\
\hline & Fourier & 17,65 & 17,59 & 20,53 \\
\hline
\end{tabular}

as situações de ondas trafegantes.

\section{CONCLUSÃO}

A principal contribuição do algoritmo apresentado é a possibilidade deste ser aplicável a qualquer linha de transmissão, independentemente das peculiaridades da mesma, sem a necessidade de ajustes adicionais nos parâmetros das RNA, ou seja, do retreinamento destas.
A etapa de pré-processamento possui um papel importante no algoritmo proposto, pois além de proporcionar que este seja independente do nível de tensão da linha, também possibilita que as RNA sejam treinadas através de um sistema monofásico de primeira ordem, simplificando e agilizando o processo de geração dos conjuntos de treinamento.

Conforme apresentado na tabela 1 , ressalta-se um fato de extrema relevância, que corresponde a capacidade das RNA filtrarem a componente exponencial, respondendo corretamente quando há ou não componente aperiódica no sinal de entrada. Nesta tabela observa-se que as RNA avaliadas responderam, com a resistência ou a reatância, com erros menores do que $5 \%$. Na maioria dos casos, erros bem inferiores a $3 \%$.

Quanto aos tempos de respostas pode-se dizer que, em termos de tempo de trip, o algoritmo proposto leva vantagem sobre o algoritmo convencional. Já com relação ao tempo de estabilização o algoritmo proposto mostrou-se a melhor opção até o nível de $345 \mathrm{kV}$, enquanto nos níveis de $500 \mathrm{kV}$ e $765 \mathrm{kV}$ o algoritmo convencional teve o melhor desempenho. Acredita-se que a limitação do algoritmo proposto, nos níveis de $500 \mathrm{kV}$ e $765 \mathrm{kV}$, ocorre porque os sinais de treinamento da RNA são provenientes de um sistema de primeira ordem, que não contempla as situações de ondas trafegantes, comum em níveis mais altos e linhas mais longas.

\section{REFERÊNCIAS}

Blackburn, J.L. (1998). Protective Relaying - Principles and Applications. New York, Marcel Dekker, 3 ed..

Bouthiba, T. (2004). Fault Location in EHV Transmission Lines Using Artificial Neural Networks. Int. J. Appl. Math. Comput. Sci., vol 14, n.1, p.69-78.

Dalstein, T.; Friedrich, T.; Kulicke, B.; Sobajic, D. (1996). Multi Neural Network Based Fault Area Estimation for High Speed Protective Relaying. IEEE Transactions on Power Delivery, vol. 11, n.2, p.740-747.

Demuth, H.; Beale, M. (1994). Neural Network Toolbox For Use With Matlab. The Math Works, 3 ed..

Horowitz, S.H.; Phadke, A.G. (1996). Power System Relaying. England, Research Studies Press, 2 ed.

Jiali, H.; Yuqian, D.; Yongli, L.; Shanshan, L. (1997). Distance Relay Protection Based on Artificial Neural Network. $4^{\text {th }}$ International Conference on Advances in Power System Control, Operation and Management, APSCOM-97, p.515-520.

Kezunovic, M.; Rikalo, I. (1996). Detect and Classify Faults Using Neural Nets. IEEE Computer Applications in Power, p.42-47. 
Li, Y.L.; Li, B.; Zhang, X.H.; He, J.L. (2001). An ANNBased Distance Protective Relays of Transmission Lines. IEE Developments in Power System Protection, n.479, p.311-314.

Oleskovicz, M.; Coury, D.V.; Carvalho, A.P.L. (1998). Artificial Neural Network Applied to Power System Protection. Vth Brazilian Symposium on Neural Networks, Belo Horizonte.

Salat, R.; Osowski, S. (2000). Fault Location in Transmission Line Using Self-Organizing Neural Network. Proceedings of ICSP2000, p.1585-1588.

Santos, R.C.; Senger, E.C. (2004). Algoritmo Baseado em Redes Neurais Artificiais para a Proteção de Distância de Linhas de Transmissão. Tese de Doutorado, EPUSP.

Senger, E.C.; Santana, N.N. (1998) . Pré-Filtragem da Componente Aperiódica Exponencial para os Algoritmos Utilizados em Relés de Distância. Seminário Técnico de Proteção e Controle - STPC.

Tawfik, M.M.; Morcos, M.M. (2001). ANN-Based Techniques for Estimating Fault Location on Transmission Lines Using Prony Method. IEEE Transactions on Power Delivery, vol. 16, n.2, p.219-224.

Vasilic, S.; Kezunovic, M. (2002). An Improved Neural Algorithm for Classifying the Transmission Line Faults. IEEE, p.918-923.

Vázquez E.; Altuve, H.J.; Chacón O.L. (1996). Neural Network Approach To Fault Detection in Electric Power Systems. IEEE International Conference on Neural Networks, vol 4, p. 2090 - 2095.

Wasserman, P.D. (1989). Neural Computing - Theory and Practice. New York, Van Nostrand Reinhold.

\section{APÊNDICE A}

Na figura 12 é apresentado o modelo simplificado, adotado neste estudo, para uma linha de transmissão trifásica. Os parâmetros $R_{n}$ e $L_{n}$ representam a impedância do caminho de retorno, percorrido pela corrente in.

O equacionamento da linha mostrada na figura 12 resulta nas equações (34) - (39), cada uma válida para um determinado tipo de falta sólida.

1. Fase $\underline{\mathbf{A}}$ em curto-circuito com a terra

$$
v_{a}^{\prime}=0 \quad \Rightarrow \quad v_{a}=R^{1} \cdot i_{a r}+L^{1} \cdot \frac{d}{d t} i_{a x}
$$

2. Fase $\underline{\mathbf{B}}$ em curto-circuito com a terra

$$
v_{b}^{\prime}=0 \quad \Rightarrow \quad v_{b}=R^{1} \cdot i_{b r}+L^{1} \cdot \frac{d}{d t} i_{b x}
$$

3. Fase $\underline{\mathbf{C}}$ em curto-circuito com a terra

$$
v_{c}^{\prime}=0 \quad \Rightarrow \quad v_{c}=R^{1} \cdot i_{c r}+L^{1} \cdot \frac{d}{d t} i_{c x}
$$

4. Curto-circuito entre as fases $\underline{\mathbf{A}}$ e $\underline{\mathbf{B}}(\mathrm{AB}$ ou $\mathrm{ABN})$

$$
v_{a b}=R^{1} \cdot\left(i_{a}-i_{b}\right)+L^{1} \cdot \frac{d}{d t}\left(i_{a}-i_{b}\right)
$$

5. Curto-circuito entre as fases $\underline{\mathbf{B}}$ e $\underline{\mathbf{C}}(\mathrm{BC}$ ou $\mathrm{BCN})$

$$
v_{b c}=R^{1} \cdot\left(i_{b}-i_{c}\right)+L^{1} \cdot \frac{d}{d t}\left(i_{b}-i_{c}\right)
$$

6. Curto-circuito entre as fases $\underline{\mathbf{C}}$ e $\underline{\mathbf{A}}(\mathrm{CA}$ ou CAN)

$$
v_{c a}=R^{1} \cdot\left(i_{c}-i_{a}\right)+L^{1} \cdot \frac{d}{d t}\left(i_{c}-i_{a}\right)
$$

onde

$$
\begin{array}{ll}
i_{a r}=i_{a}+K r \cdot i^{o}, & i_{a x}=i_{a}+K x \cdot i^{o}, \\
i_{b r}=i_{b}+K r \cdot i^{o}, & i_{b x}=i_{b}+K x \cdot i^{o}, \\
i_{c r}=i_{c}+K r \cdot i^{o}, & i_{c x}=i_{c}+K x \cdot i^{o},
\end{array}
$$

sendo,

- $K r=\frac{R^{0}-R^{1}}{R^{1}}=\frac{r^{0}-r^{1}}{r^{1}}$

- $K x=\frac{L^{0}-L^{1}}{L^{1}}=\frac{l^{0}-l^{1}}{l^{1}}$

- $R^{1}, R^{0}=$ Resistências de seqüência positiva e zero do trecho com defeito (Ohms);

- $r^{1}, r^{0}=$ Resistências de seqüência positiva e zero da linha $(\mathrm{Ohms} / \mathrm{km})$;

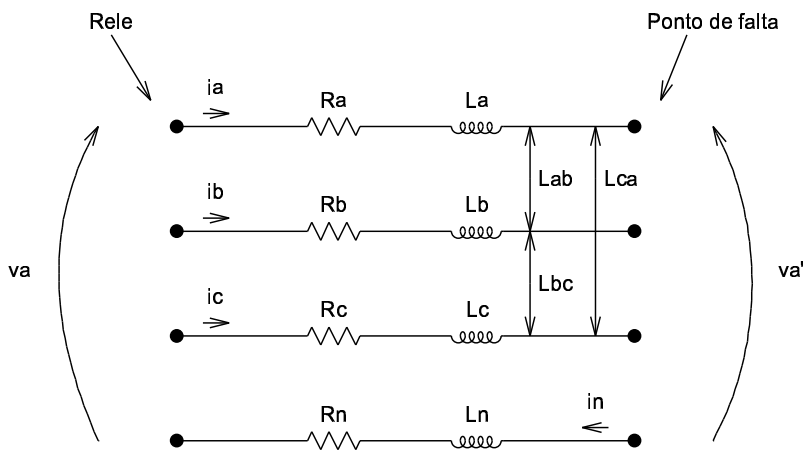

Figura 12: Modelo adotado para deduzir os vetores de entrada das RNA 
- $L^{0}, L^{1}=$ Indutâncias de seqüência positiva e zero do trecho com defeito (Ohms);

- $l^{0}, l^{1}=$ Indutâncias de seqüência positiva e zero da linha $(\mathrm{Ohms} / \mathrm{km})$;

- $v_{a}, v_{b}$ e $v_{c}=$ Tensão nas fases $\underline{\mathbf{A}}, \underline{\mathbf{B}}$ e $\underline{\mathbf{C}}$ no local do relé;

- $v_{a}{ }^{\prime}, v_{b}$ ' e $v_{c}{ }^{\prime}=$ Tensão nas fases $\underline{\mathbf{A}}, \underline{\mathbf{B}}$ e $\underline{\mathbf{C}}$ no local da falta;

- $i_{a}, i_{b}$ e $i_{c}=$ Corrente de linha nas fases $\underline{\mathbf{A}}, \underline{\mathbf{B}}$ e $\underline{\mathbf{C}}$;

- $i^{0}=$ Corrente de sequiência zero;

- $K r$ e $K x=$ Fator de compensação. 